\title{
Article \\ Influence of Component Ratio on Thermal and Mechanical Properties of Terpenoid-Sulfur Composites
}

\author{
Charini P. Maladeniya and Rhett C. Smith * D \\ Department of Chemistry and Center for Optical Materials Science and Engineering Technology, \\ Clemson University, Clemson, SC 29634, USA; cmalade@g.clemson.edu \\ * Correspondence: rhett@clemson.edu
}

Citation: Maladeniya, C.P.; Smith, R.C. Influence of Component Ratio on Thermal and Mechanical Properties of Terpenoid-Sulfur Composites. J. Compos. Sci. 2021, 5, 257. https:// doi.org $/ 10.3390 /$ jcs5100257

Academic Editor:

Francesco Tornabene

Received: 18 August 2021

Accepted: 23 September 2021

Published: 28 September 2021

Publisher's Note: MDPI stays neutral with regard to jurisdictional claims in published maps and institutional affiliations.

Copyright: (c) 2021 by the authors. Licensee MDPI, Basel, Switzerland. This article is an open access article distributed under the terms and conditions of the Creative Commons Attribution (CC BY) license (https:/ / creativecommons.org/licenses/by/ $4.0 /)$.

\begin{abstract}
Terpenoids are potentially sustainable replacements for petrochemical olefins. Sulfur is a waste product produced in large quantities from fossil fuel refining. Several composites with attractive properties have recently been made from terpenoids and sulfur. This report details the extent to which the ratio of sulfur to terpenoid and the terpenoid olefin content influences the thermal and mechanical properties of such terpenoid-sulfur composites. The terpenoids selected were diunsaturated geraniol and triunsaturated farnesol that, upon their inverse vulcanization with elemental sulfur, yield composites GerS and $_{\mathbf{x}}$ FarS $\mathbf{x}$, respectively ( $x=$ wt $\%$ sulfur). The wt $\%$ sulfur in the monomer feed was varied from 30-95 for this study, providing twelve materials. Mechanical analysis of these materials was undertaken by compressive and tensile strength techniques. Differential scanning calorimetric analysis revealed both polymeric and orthorhombic sulfur present in the materials with glass transition temperatures $\left(T_{\mathrm{g}}\right)$ of $-37{ }^{\circ} \mathrm{C}$ to $-13^{\circ} \mathrm{C}$ and melt temperatures $\left(T_{\mathrm{m}}\right)$ of 119 to $104{ }^{\circ} \mathrm{C}$. The crystallinity of composites decreases as the weight fraction of sulfur decreases and composites having the highest olefin content exhibit no detectable crystalline microstructures. The compressive strength of the materials showed increasing strength for higher olefin-content materials for both GerS $_{\mathbf{x}}$ (with compressive strength of up to $32 \mathrm{MPa}$ ) and FarS $_{\mathbf{x}}$ (with compressive strength of up to $43 \mathrm{MPa}$ ). The improved strength with increasing olefin content levels off at around $80-85 \%$ of terpenoid, after which point both tensile and compressive strength diminish.
\end{abstract}

Keywords: sustainable composite; terpenoid; sulfur; hybrid organic-inorganic composite; sulfur cement; polymer cement

\section{Introduction}

Terpenoids are biologically-sourced olefins that hold great promise for supplanting fossil fuel-derived olefins in tars and bitumen used in asphalt, in polymers, and in related composite materials [1-9]. In previous work we demonstrated that monoalkene, diene and triene terpenoids react with sulfur to yield durable composites having compressive strengths that can exceed that of ordinary Portland cement (OPC) $[10,11]$. Sulfur is a waste product of fossil fuel refining, and significant efforts have been made to uncover value-added applications for it [12-18]. One avenue for sulfur valorization is to employ it as a component of sulfur cements [19-24]. Sulfur's reactivity with olefins is driven by thermal formation of sulfur-centered radicals (Scheme 1). When sulfur is used as the majority component in reactions with olefins, high sulfur-content materials (HSMs) are formed in a process known as inverse vulcanization [12-17]. These HSMs are often composites wherein some free sulfur is trapped within a cross-linked network of organics linked by oligomeric or polymeric sulfur catenates [11,18,25-40]. Sulfur catenates are generally unstable and revert back to the orthorhombic, eight-membered ring allotrope under ambient conditions [41]. When trapped within a network solid, however, the polymeric catenates can be stabilized, thus affording the composite with strength typical of more traditional carbon-catenate-backbone materials. 


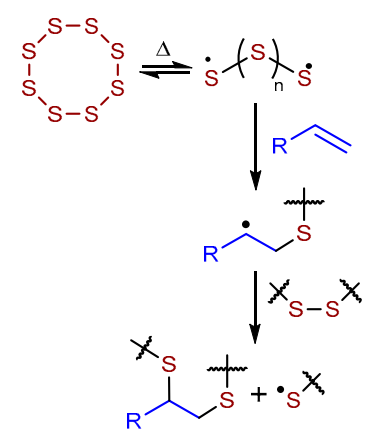

Scheme 1. Thermal reaction of elemental sulfur to produce radicals allows their subsequent reaction with olefins to form cross-linked high sulfur-content materials (HSMs) by inverse vulcanization.

Our prior work on terpenoid-sulfur composites revealed that diene and triene terpenoids geraniol and farnesol underwent intramolecular cyclization reactions in addition to the expected inverse vulcanization shown in Scheme 1 [10]. Microstructures for the geraniol-sulfur composites GerS $\mathbf{x}_{\mathbf{x}}$ and farnesol-sulfur composites FarS $_{\mathbf{x}}(\mathrm{x}=\mathrm{wt} \% \mathrm{~S}$ in the monomer feed) were thus determined to be those shown in Scheme 2. Compared to simple inverse vulcanization in which each starting material olefinic carbon is expected to form a crosslink via $\mathrm{C}-\mathrm{S}$ bond-formation, the intramolecular cyclization pathway lowers the number of olefinic carbons in the starting material that end up in C-S in the product. The lower crosslink density in composites formed using cyclization-prone terpenoids resulted in their lower mechanical strength compared to other olefin-sulfur composites in which there is no evidence for such cyclization.
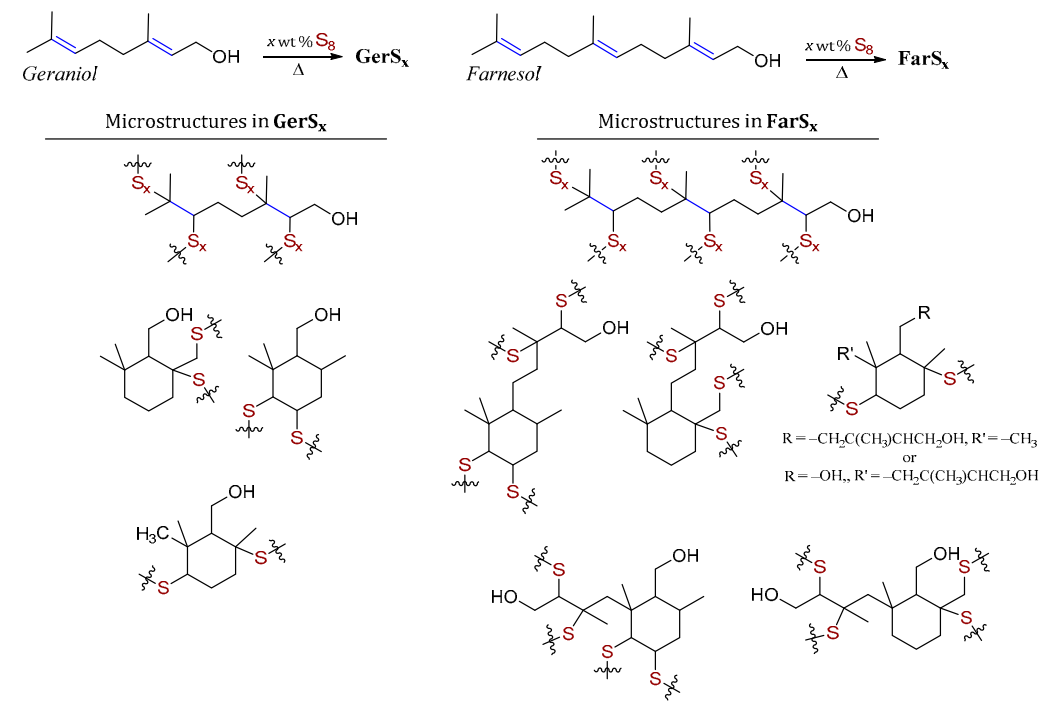

Scheme 2. Reaction of terpenoids such as geraniol and farnesol with sulfur leads to HSMs GerS $_{\mathbf{x}}$ and FarS $_{\mathbf{x}}$ comprising several microstructures resulting from a combination of inverse vulcanization and intramolecular cyclization reactions.

The preliminary work on terpenoid-sulfur composites described above employed a 90:10 sulfur-to-terpenoid monomer feed ratio. For the current work, it was of interest to evaluate the extent to which terpenoid-sulfur composite mechanical and thermal properties could be tuned by adjusting the comonomer feed ratio. Previous studies on other HSMs suggest that the tensile and compressive strength profiles, crystallinity and thermal properties are all significantly impacted by at times small changes in the olefin content. Herein were studied terpenoid sulfur composites employing diolefin terpenoid geraniol $\left(\mathbf{G e r S}_{\mathbf{x}}\right)$ and triolefin terpenoid farnesol $\left(\right.$ FarS $\left._{\mathbf{x}}\right)$, where the wt $\%$ sulfur was varied from $50-95 \%$. The influence of comonomer ratio on tensile strength, compressive strength, morphological 
changes and thermal stability of the composites were evaluated. This is the first report in which the influence of olefin content on either the mechanical or morphological properties of terpenoid-sulfur cement composites has been evaluated, and as such provides guidance for the design of such materials for future applications.

\section{Materials and Methods}

\subsection{General Considerations}

Thermogravimetric analysis (TGA) was recorded on a Mettler Toledo TGA 2 STAR System over the range of 25 to $800{ }^{\circ} \mathrm{C}$ with a heating rate of $5{ }^{\circ} \mathrm{C} \mathrm{min}^{-1}$ under a flow of $\mathrm{N}_{2}\left(20 \mathrm{~mL} \mathrm{~min}^{-1}\right)$. Differential Scanning Calorimetry (DSC) data were acquired using a Mettler Toledo DSC 3 STAR $^{\mathrm{e}}$ System over the range of -60 to $140{ }^{\circ} \mathrm{C}$, with a heating rate of $5{ }^{\circ} \mathrm{C} \mathrm{min}$ min $^{-1}$ under a flow of $\mathrm{N}_{2}\left(200 \mathrm{~mL} \mathrm{~min}^{-1}\right)$. Each DSC measurement was carried out over three heat-cool cycles to screen out thermal history. The data reported were taken from the third cycle of the experiment.

Compressive measurements were acquired on cylinders (Figure 1) using a Mark-10 ES30 Manual Test Stand equipped with a Mark 10 M3-200 Force Gauge by a modified ASTM C39 standard. Terpenoid-sulfur composite materials were aged for $4 \mathrm{~d}$ prior to compressive strength testing. The $4 \mathrm{~d}$ aging period was selected after assessing material properties over shorter and longer times for one set of samples and the properties were levelled off after $4 \mathrm{~d}$. Longer-term stability is not known for these materials (Figure S2, Supplementary Materials).

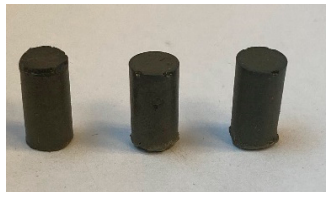

(a)

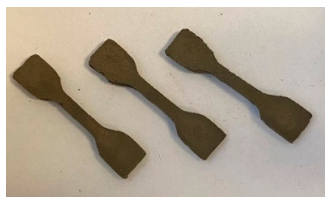

(b)

Figure 1. (a) Representative photos of compressive cylinders and (b) of tensile strength dog-boneshaped test samples of terpenoid-sulfur composites.

Tensile measurements were taken on dog bone-shaped samples (Figure 1) with a Mark-10 ES30 Manual Test Stand equipped with a Mark 10 Force Gauge (Model M3-2 or Model M3-200). The tensile specimens were clamped down with a Mark 10 wedge grip (Model G1061-1). Tensile specimens were cut or moulded into dog bone shapes with dimensions as depicted in Figure S3 of the Supplementary Materials. Samples of I-BPA 80 were approximately $1.2 \mathrm{~mm}$ in thickness, while R-BPA 80 samples were approximately $2.5 \mathrm{~mm}$ in thickness. The actual thicknesses were individually measured at positions on each sample using callipers and average values were used for calculations. The data reported are an average of runs on five different samples.

\subsection{Chemical Precursor Sources}

Terpenoids (Alfa Aesar (Ward Hill, MA, USA) or Sigma-Aldrich (St. Louis, MO, USA)) and elemental sulfur (99.5\%, Alfa Aesar) were used without further purification.

\subsection{General Synthesis of Terpenoid-Sulfur Composites}

CAUTION: Heating elemental sulfur with organics can result in the formation of $\mathrm{H}_{2} \mathrm{~S}$ gas. $\mathrm{H}_{2} \mathrm{~S}$ is toxic, foul-smelling, and corrosive. Elemental sulfur was weighed directly into a $250 \mathrm{~mL}$ Erlenmeyer flask. The vessel was placed in a thermostat-controlled oil bath set to $180^{\circ} \mathrm{C}$. After about 2-3 min, the sulfur had visibly melted and become a dark orange colour. The requisite terpenoid was added to the flask and the reaction media was vigorously stirred with an overhead mechanical stirrer equipped with a stainless-steel stir rod and vane for $35 \mathrm{~min}$, over which time the colour changed to brown/black. After cooling to room temperature, the materials were rigid brown to black solids that were all readily 
remeltable and could be shaped into compressive test cylinders or tensile test dog bones by simply pouring into silicone moulds.

\section{GerS $_{95}$}

This material was made according to the general procedure described above using $19.07 \mathrm{~g}$ of sulfur and $1.66 \mathrm{~g}$ of geraniol. Yield: quantitative. Elemental analysis calculated: C, 3.88\%; S, 95\%; H, 0.58\%. Found: C, 4.94\%; S, 94.21\%; H, 0.35\%.

\section{GerS 90}

This material was made according to the general procedure described above using $18.05 \mathrm{~g}$ of sulfur and $2.21 \mathrm{~g}$ of geraniol. Yield: quantitative. Elemental analysis calculated: C, 7.78\%; S, 90\%; H, 1.17\%. Found: C, 7.86\%; S, 89.45\%; H, 0.90\%.

\section{$\mathrm{GerS}_{85}$}

This material was made according to the general procedure described above using $17.14 \mathrm{~g}$ of sulfur and $3.49 \mathrm{~g}$ of geraniol. Yield: quantitative. Elemental analysis calculated: C, $11.67 \%$; S, $85 \%$; H, $1.75 \%$. Found: C, $10.98 \%$; S, $86.72 \%$; $\mathrm{H}, 1.25 \%$.

\section{$\mathrm{GerS}_{80}$}

This material was made according to the general procedure described above using $16.17 \mathrm{~g}$ of sulfur and $4.16 \mathrm{~g}$ of geraniol. Yield: quantitative. Elemental analysis calculated: C, $15.56 \%$; S, 80\%; H, 2.33\%. Found: C, $15.68 \%$; S, 81.67\%; H, $1.84 \%$.

\section{GerS $_{70}$}

This material was made according to the general procedure described above using $14.17 \mathrm{~g}$ of sulfur and $6.19 \mathrm{~g}$ of geraniol. Yield: quantitative. Elemental analysis calculated: C, $23.34 \%$; S, 70\%; H, 3.5\%. Found: C, 25.44\%; S, 70.19\%; H, 2.51\%.

\section{FarS 95}

This material was made according to the general procedure described above using $19.07 \mathrm{~g}$ of sulfur and $1.17 \mathrm{~g}$ of geraniol. Yield: quantitative. Elemental analysis calculated: C, $4.05 \% ; \mathrm{S}, 95 \% ; \mathrm{H}, 0.58 \%$. Found: C, $4.67 \%$; S, 94.55\%; H, $0.35 \%$.

\section{FarS 90}

This material was made according to the general procedure described above using $18.25 \mathrm{~g}$ of sulfur and $2.34 \mathrm{~g}$ of geraniol. Yield: quantitative. Elemental analysis calculated: C, $8.1 \%$; S, 90\%; H, 1.18\%. Found: C, 7.59\%; S, 89.44\%; H, 0.89\%.

\section{FarS $_{85}$}

This material was made according to the general procedure described above using $17.01 \mathrm{~g}$ of sulfur and $3.52 \mathrm{~g}$ of geraniol. Yield: quantitative. Elemental analysis calculated:

C, $12.14 \%$; S, $85 \% ; H, 1.75 \%$. Found: C, $17.83 \% ;$ S, 78.86\%; H, 2.04\%.

\section{FarS $_{80}$}

This material was made according to the general procedure described above using $16.18 \mathrm{~g}$ of sulfur and $4.61 \mathrm{~g}$ of geraniol. Yield: quantitative. Elemental analysis calculated:

C, $16.19 \%$; S, 80\%; H, 2.33\%. Found: C, 19.68\%; S, 77.04\%; H, 1.76\%.

\section{FarS $_{70}$}

This material was made according to the general procedure described above using $14.33 \mathrm{~g}$ of sulfur and $7.04 \mathrm{~g}$ of geraniol. Yield: quantitative. Elemental analysis calculated: C, $24.28 \%$; S, 70\%; H, 3.51\%. Found: C, 28.78\%; S, 69.2\%; H, 3.54\%.

\section{FarS $_{60}$}

This material was made according to the general procedure described above using $12.23 \mathrm{~g}$ of sulfur and $9.39 \mathrm{~g}$ of geraniol. Yield: quantitative. Elemental analysis calculated: C, $32.38 \%$; S, 60\%; H, 4.68\%. Found: C, 36.03\%; S, 57.83\%; H, 4.73\%.

\section{FarS 50}

This material was made according to the general procedure described above using $10.25 \mathrm{~g}$ of sulfur and $11.47 \mathrm{~g}$ of geraniol. Yield: quantitative. Elemental analysis calculated: C, $40.47 \%$; S, 50\%; H, 5.85\%. Found: C, 40.46\%; S, 52\%; H, 5.96\%. 


\section{Results and Discussion}

\subsection{Synthesis and Thermal Properties}

Preparation of terpenoid-sulfur composites was accomplished by the reaction of each terpenoid with molten elemental sulfur at $180^{\circ} \mathrm{C}$ for $35 \mathrm{~min}$ in the absence of any other added solvents or reagents according to the procedure we previously reported for the preparation of $\mathbf{G e r S}_{\mathbf{9 0}}$ and $\mathbf{F a r S}_{\mathbf{9 0}}$ [10]. Reactions of farnesol with 5, 10, 15, 20, 30, 40 and $50 \mathrm{wt} \%$ sulfur all produced rigid homogeneous solids FarS $\mathbf{x}(x=w t \% S)$ ranging in color from brown to black (Figure 1). Geraniol reacted with 5, 10, 15, 20 and $30 \mathrm{wt} \%$ sulfur to produce materials GerS $_{\mathbf{x}}$ similar in appearance to FarS $_{\mathbf{x}}$. When analogous reactions of geraniol with 40 or $50 \mathrm{wt} \% \mathrm{~S}$ were undertaken in an effort to prepare $\mathbf{G e r S}_{40}$ and $\mathbf{G e r S}_{50}$, however, some geraniol separated from the initially-isolated solids after several hours. These materials were thus not further evaluated in this study. All of the materials listed in Table 1 were remeltable solids that could be readily poured into silicone moulds for shaping following reported protocols.

Table 1. Thermal properties of terpenoid-sulfur composites and comparison to elemental sulfur (orthorhombic).

\begin{tabular}{|c|c|c|c|c|c|}
\hline Materials & $T_{\mathrm{g}} /{ }^{\circ} \mathrm{C}$ & $T_{\mathrm{m}} /{ }^{\circ} \mathrm{C}$ & $\begin{array}{c}\Delta H_{m}(\mathrm{a}) \\
\mathrm{J} / \mathrm{g}\end{array}$ & $\begin{array}{c}\Delta H_{c c}(\mathrm{~b}) \\
\mathrm{J} / \mathrm{g}\end{array}$ & $\begin{array}{c}\text { Percent } \\
\text { Crystallinity (c) }\end{array}$ \\
\hline $\mathrm{S}_{8}$ & NA & 119 & 45 & NA & 100 \\
\hline GerS $_{95}$ & -38 & 113 & 33 & 22 & 27 \\
\hline GerS $_{90}$ & -37 & 116 & 25 & 20 & 23 \\
\hline $\mathrm{GerS}_{85}$ & -37 & 104 & 33 & 24 & 20 \\
\hline $\mathrm{GerS}_{80}$ & -11 & NA & NA & NA & 0 \\
\hline $\mathrm{GerS}_{70}$ & -13 & NA & NA & NA & 0 \\
\hline FarS $_{95}$ & -38 & 117 & 36 & 31 & 12 \\
\hline FarS $_{90}$ & -37 & 105 & 25 & 21 & 10 \\
\hline FarS $_{85}$ & -4.5 & 112 & 14 & 12 & 6.7 \\
\hline FarS $_{80}$ & 4.6 & 108 & 5.5 & NA & 0 \\
\hline $\mathrm{FarS}_{70}$ & 5.0 & 111 & NA & NA & 0 \\
\hline FarS $_{60}$ & 2.7 & NA & NA & NA & 0 \\
\hline $\mathrm{FarS}_{50}$ & 8.5 & NA & NA & NA & 0 \\
\hline
\end{tabular}

(a) Integrated heat of melting for the orthorhombic sulfur melt transition. (b) Integrated area for all cold crystallization transitions. (c) The reduction in percent crystallinity of each samples was calculated with respect to sulfur (normalized to $100 \%$ ).

Differential scanning calorimetry (DSC, Table 1) was used to analyze the thermalmorphological properties of the materials. Some of the characteristics of HSMs often observed in their DSC analysis include a glass transition temperature $\left(T_{\mathrm{g}}\right)$ near $-37^{\circ} \mathrm{C}$ diagnostic for the presence of polymeric sulfur domains, a melting temperature $\left(T_{\mathrm{m}}\right)$ near $118{ }^{\circ} \mathrm{C}$ for orthorhombic sulfur trapped but not covalently incorporated into the composite, monoclinic-orthorhombic transition near $106^{\circ} \mathrm{C}$ if trapped monoclinic sulfur is present, and cold crystallization features between -40 and $80^{\circ} \mathrm{C}$. These features are typical for HSMs made from a wide range of monomers [42-47].

The morphological changes in the geraniol-sulfur composites as a function of monomer composition are clear from the DSC traces shown in Figure 2 and summarized in Table 1. The very high sulfur loading in $\mathrm{GerS}_{95}$ leads to a material that exhibits all of the general features noted above: a glass transition indicating the presence of polymeric sulfur domains observed at $-38^{\circ} \mathrm{C}$, several cold crystallization peaks observed between 3 and $65^{\circ}$ $\mathrm{C}$, the monoclinic-orthorhombic transition observed at $104{ }^{\circ} \mathrm{C}$ and the orthorhombic sulfur melt transition observed at $113^{\circ} \mathrm{C}$. The slight melting point depression from $118{ }^{\circ} \mathrm{C}$ for pure orthorhombic sulfur is typical. In $\mathrm{GerS}_{90}$ and $\mathrm{GerS}_{\mathbf{8 5}}$ materials having additional organic crosslinker the glass transition for polymeric sulfur is still present at $-37^{\circ} \mathrm{C}$ and the cold crystallization peaks progressively coalesce to a more well-defined peak centered at $37^{\circ} \mathrm{C}$ in the thermogram for $\mathrm{GerS}_{\mathbf{8 5}}$. The sharpening of the crystallization temperature is consistent with fewer types of crystallizable domains that would be expected in the presence of progressively more confining cross-links. The monoclinic-to-orthorhombic 
transition observed in $\mathrm{GerS}_{95}$ is also absent in $\mathrm{GerS}_{90}$ and $\mathrm{GerS}_{\mathbf{8 5}}$, consistent with the smaller pockets of free volume in more crosslinked materials and the greater volume required for the conformation of $\mathrm{S}_{8}$ rings in the monoclinic crystal morphology. A dramatic change in the thermal-morphological properties of the $\mathbf{G e r S}_{\mathbf{x}}$ materials takes place between 20 and $30 \mathrm{wt} \%$ geraniol monomer. The DSC analysis for $\mathrm{GerS}_{\mathbf{8 0}}$ and $\mathrm{GerS}_{70}$ lack cold crystallization and orthorhombic sulfur melt features, indicating that in these materials the olefin content is high enough to fully react with and covalently incorporate the sulfur comonomer. Multiple, broad/overlapping glass transition features are observed spanning the range from -40 to $-5^{\circ} \mathrm{C}$, with midpoints at -11 and $-13{ }^{\circ} \mathrm{C}$ for $\mathrm{GerS}_{80}$ and $\mathrm{GerS}_{70}$, respectively, followed by a broad melting transition from around 55 to $135^{\circ} \mathrm{C}$ in both $\mathrm{GerS}_{80}$ and $\mathrm{GerS}_{70}$. The broadness of the features is similar to analogous transitions observed in some other HSMs with high olefin content [48] and is perhaps unsurprising given the variety of microstructural subunits contributing to the materials' morphologies.
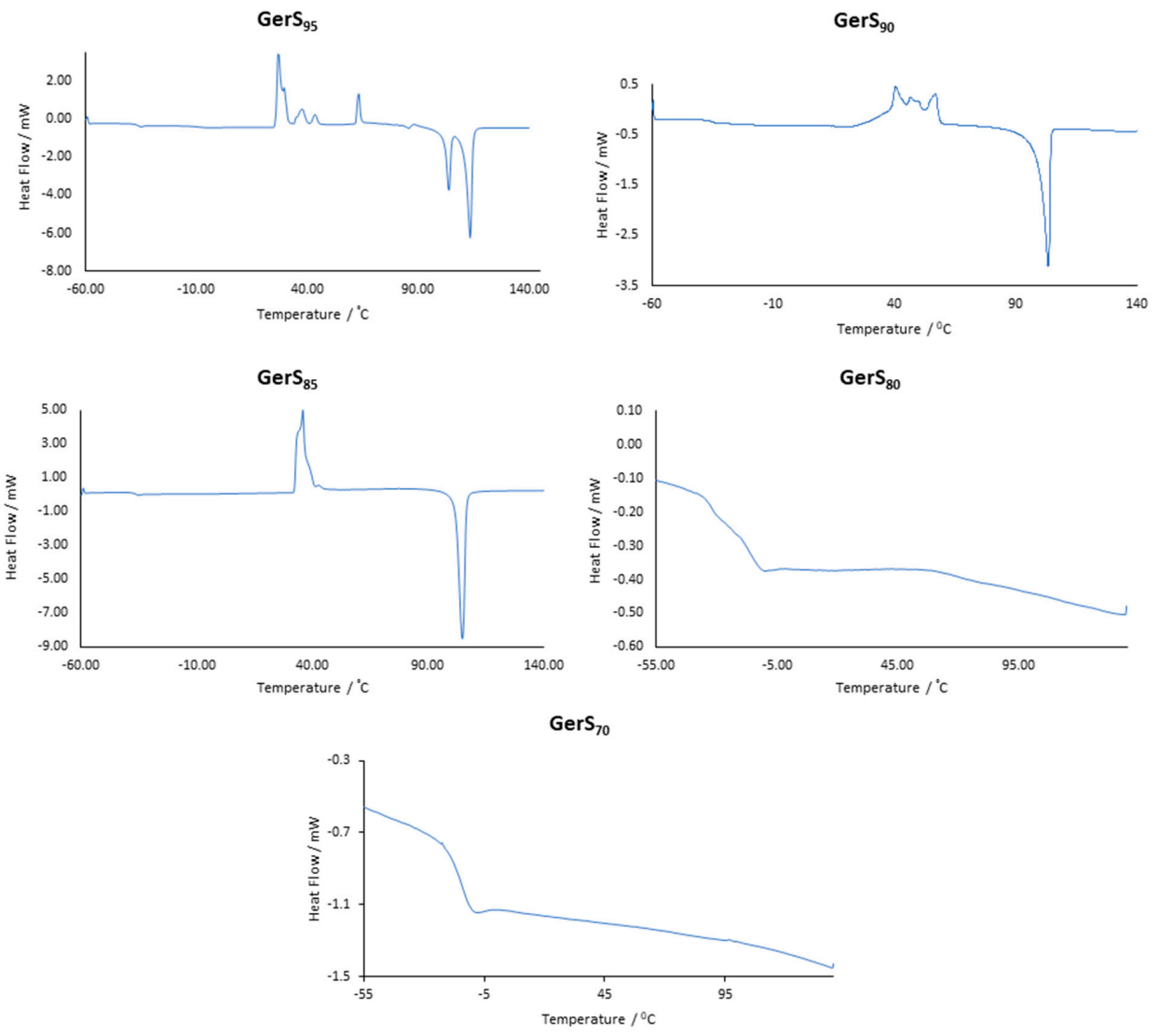

Figure 2. DSC traces for the third heating curves for GerS $\mathbf{x}$. Analogous traces for the FarS $\mathbf{S}_{\mathbf{x}}$ series of composites are provided in the Supplementary Materials (Figure S1).

The DSC analysis of farnesol-sulfur composites FarS $\mathbf{x}$ (Figure S1, Supplementary Materials) showed some similar trends to those observed for GerS $_{x}$, but with some notable differences as well. First, no cold crystallization features or $T_{\mathrm{g}}$ were observed in the DSC analysis of $\mathbf{F a r S}_{95}$, while the monoclinic-orthorhombic transition $\left(104{ }^{\circ} \mathrm{C}\right)$ and orthorhombic sulfur melt $\left(117^{\circ} \mathrm{C}\right)$ features are prominent. The orthorhombic sulfur melt peak and the glass transition for polymeric sulfur were also observed in $\mathbf{F a r S}_{\mathbf{9 0}}$, which additionally exhibited a relatively narrow cold crystallization feature centered at $49^{\circ} \mathrm{C}$. The cold crystallization and orthorhombic melt features are also observed with progressive broadening as olefin content increases (similar to that observed for GerS $_{\mathbf{x}}$ materials) for FarS $_{85}$ and $\mathbf{F a r S}_{\mathbf{8 0}}$. The $T_{\mathrm{g}}$ for polymeric sulfur is absent from DSC analysis of FarS $\mathbf{x}$ materials having $>20 \mathrm{wt} \%$ farnesol in the monomer feed, which can be reasonably attributed to the ever-shorter sulfur catenates with increasing olefin cross-linker content. A new $T_{\mathrm{g}}$ is 
observed attributable to the organosulfur network comprising oligosulfur catenates and farnesol microstructures shown in Scheme 2. The $T_{\mathrm{g}}$ progressively shifts from $-4.5^{\circ} \mathrm{C}$ in $\mathrm{FarS}_{\mathbf{8 5}}$ to $+8.5^{\circ} \mathrm{C}$ in $\mathbf{F a r S}_{\mathbf{5 0}}$. As the $\mathrm{T}_{\mathrm{g}}$ continues to shift and the DSC curve continues to flatten as a result of crystallization and melting peaks shrinking as farnesol content increases from 20 to $50 \mathrm{wt} \%$. Quantification of crystallinity for FarS $_{\mathbf{x}}$ and comparison to pure sulfur by integration of thermal features according to Equation (1) also reflects the diminished contribution of crystalline orthorhombic or polymeric sulfur domains to the structures.

$$
\Delta \chi_{c}=1-\left\{\frac{\Delta H_{m}-\Delta H_{c c}}{\Delta H_{m(S)}-\Delta H_{c c}(S)}\right\} * 100 \%
$$

where $\Delta \chi_{c}$ is change of percentage crystallinity with respect to sulfur, $\Delta H_{m}$ is melting enthalpy of composite material, $\Delta H_{c c}$ is cold crystallization enthalpy of composite material, $\Delta H_{m(S)}$ is melting enthalpy of sulfur and $\Delta H_{c c(S)}$ is cold crystallization enthalpy of sulfur. A comparison of the percent crystallinity values for $\mathbf{F a r S}_{\mathbf{x}}$ to the values for $\mathbf{G e r S}_{\mathbf{x}}$ analogues comprising the same wt \% terpenoid in the monomer feed reveals lower percent crystallinity for the FarS $_{\mathbf{x}}$ materials, reinforcing the trend that more olefin content generally leads to less crystalline materials in HSMs for a wide range of olefin linkers. It is also noteworthy that the disappearance of the polymeric sulfur $T_{\mathrm{g}}$ in $\mathbf{F a r S}_{\mathbf{x}}$ occurred between 10 and 15\% terpenoid monomer feed, whereas this occurred between 15 and 20 wt \% terpenoid monomer feed for the $\mathbf{G e r S}_{\mathbf{x}}$ materials, again attributable to greater crosslinking afforded by triunsaturated farnesol versus the diunsaturated geraniol.

\subsection{Mechanical Properties}

Previous work has established that the mechanical strength (compressive, flexural or tensile) of HSMs generally increases with increasing olefin linker content until a levellingoff point at which the HSM becomes more brittle and thus fragments at lower strain [49]. It was therefore of interest to determine the ratio of terpenoid to sulfur that would achieve the maximum compressive and tensile strength for FarS $_{\mathbf{x}}$ and $\mathbf{G e r S}_{\mathbf{x}}$.

The compressive strength trends (Figure 3a and Table 2) for $\mathbf{G e r S}_{\mathbf{x}}$ and $\mathbf{F a r S}_{\mathbf{x}}$ illustrate first that for a given weight percent sulfur composition the farnesol-derived composites are stronger than the corresponding geraniol-derived materials due to the differences in crosslinking units in the two terpenoids. Both series $\mathbf{G e r S}_{\mathbf{x}}$ and FarS $_{\mathbf{x}}$ appear to level off after $20 \mathrm{wt} \%$ terpenoid is added to the mixture, though the trend could not be evaluated for higher percent terpenoid-composition materials because attempts to use the conditions employed for the other materials to obtain materials with increased terpenoid content further let to phase-separation following reaction.

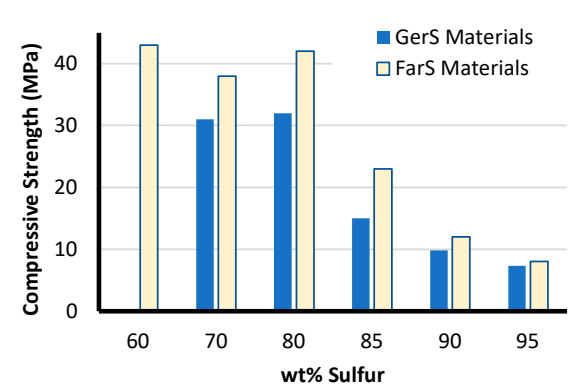

(a)

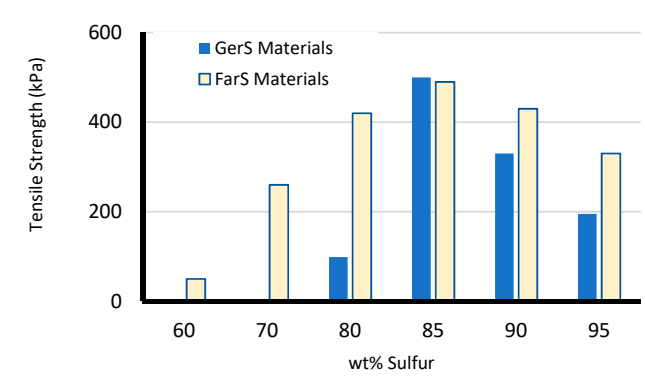

(b)

Figure 3. Comparison of (a) compressive strength and (b) tensile strength as a function of terpenoid identity and monomer feed composition. 
Table 2. Mechanical properties of terpenoid-sulfur composites.

\begin{tabular}{|c|c|c|c|c|c|}
\hline \multirow[b]{2}{*}{ Materials } & \multicolumn{2}{|c|}{ Compressive Tests } & \multicolumn{3}{|c|}{ Tensile Tests } \\
\hline & Strength (MPa) & $\begin{array}{l}\text { St.dev. (b) } \\
\text { (MPa) }\end{array}$ & Strength (kPa) & $\begin{array}{l}\text { St.dev. (b) } \\
\quad(\mathrm{kPa})\end{array}$ & $\begin{array}{c}\text { Elongation at Break } \\
(\%)\end{array}$ \\
\hline $\mathrm{OPC}^{(a)}$ & 17 & NA & 1400 & NA & - \\
\hline GerS $_{95}$ & 7.3 & 0.3 & 195 & 4 & 1 \\
\hline $\mathrm{GerS}_{90}$ & 9.8 & 0.6 & 330 & 12 & 3 \\
\hline $\mathrm{GerS}_{85}$ & 15 & 1 & 750 & 40 & 5 \\
\hline $\mathrm{GerS}_{80}$ & 32 & 1 & 99 & 4 & 36 \\
\hline $\mathrm{GerS}_{70}$ & 31 & 1 & NA & NA & NA \\
\hline FarS $_{95}$ & 10 & 1 & 330 & 20 & 23 \\
\hline FarS $_{90}$ & 8 & 1 & 430 & 30 & 5 \\
\hline FarS $_{85}$ & 12 & 1 & 490 & 12 & 4 \\
\hline FarS $_{80}$ & 23 & 1 & 420 & 9 & 1 \\
\hline FarS $_{70}$ & 42 & 2 & 260 & 4 & 5 \\
\hline $\mathrm{FarS}_{60}$ & 38 & 4 & 50 & 3 & 36 \\
\hline FarS $_{50}$ & 43 & 3 & NA & NA & NA \\
\hline
\end{tabular}

(a) Values for residential building-grade ordinary portland cement for foundations and footings. (b) Standard deviation for the measurements.

Tensile strengths were lower than that of OPC (Figure 3b and Table 2) and followed a somewhat different trend than was observed in the compressive strengths. First, the GerS $_{\mathbf{x}}$ materials were too brittle to even be clamped into the instrument without breaking when the sulfur content was below $80 \mathrm{wt} \%$. The tensile strength of measurable GerS $\mathbf{S}_{\mathbf{x}}$ materials reflected increased tensile strength with increasing crosslinking from GerS $\mathbf{9}_{\mathbf{9}}$ to $\mathrm{GerS}_{85}$ before the sudden drop in tensile strength between $\mathrm{GerS}_{85}$ and $\mathrm{GerS}_{80}$. This drop in tensile strength was accompanied by a notable increase in elongation at break from $5 \%$ to $36 \%$. This change in mechanical properties also mirrors the distinct change in morphology between $\mathbf{G e r S}_{\mathbf{8 5}}$ and $\mathbf{G e r S}_{\mathbf{8 0}}$ observed from the DSC data (Figure 2) discussed above. The brittleness reflected in the low elongation at break for materials comprising more sulfur appears to be attributable to the crystallinity of those materials, while the amorphous material that are above $\mathrm{T}_{\mathrm{g}}$ at room temperature shows significantly higher elongation at break as would be anticipated. The tensile strength data for FarS $\mathbf{x}_{\mathbf{x}}$ composites showed trends similar to those observed in the $\mathbf{G e r S}_{\mathbf{x}}$ materials. The FarS $\mathbf{S}_{\mathbf{x}}$ materials generally have higher ultimate tensile strengths but similar elongations at break when compared to their $\mathbf{G e r S}_{\mathbf{x}}$ analogues comprising the same wt \% of sulfur. FarS $\mathrm{x}_{\mathbf{x}}$ materials were notably stronger at lower terpenoid loading due to higher cross-linking but the ultimate tensile strength levels off at about the same strength and at the same amount of sulfur ( $85 \mathrm{wt} \%$ ) as the GerS $_{\mathbf{x}}$ materials, suggesting a possible ultimate limit for these classes of materials. The compressive strengths of the strongest previously-reported HSMs was up to around $35 \mathrm{MPa}$, $[25,30,49,50]$ so materials FarS $50-70$ appear to have the highest compressive strengths of any HSMs for which data has been reported.

\section{Conclusions}

In conclusion, increased organic content facilitates cross-linking with elemental sulfur in terpenoid-sulfur composites, leading to concomitantly improved mechanical properties of the composites. The compressive strength of these composites (up to $43 \mathrm{MPa}$ ) is significantly greater than that of ordinary Portland cement, while terpenoid-sulfur composite tensile strength (up to $750 \mathrm{kPa}$ ) is notably lower than that of ordinary Portland cement. A higher olefin content is found to progressively improve the strength of composites until around $80-85 \%$ of terpenoid, after which point both tensile and compressive strength diminish as the length of polymeric sulfur chains in the network are expected to concomitantly decrease. The crystallinity of composites also decreases with increasing olefin content, such that composites having the highest olefin content no longer exhibit detectable crystalline microstructures. The mechanical metrics make terpenoid-sulfur composites 
potential candidates for static load-bearing applications like footings and foundations where less sustainably produced mineral cements might otherwise be employed.

Supplementary Materials: The following are available online at https:/ / www.mdpi.com/article / 10.3390/jcs5100257/s1: Figure S1. DSC traces for farnesol-sulfur composites FarSx. The traces are given for the third heating cycle; Figure S2. Annotated photographs depicting the manner in which terpenoid-sulfur composites were fabricates for compressive testing. Image is for a sample of GerS90. Reproduced from C. P. Maladeniya, M. S. Karunarathna, M. K. Lauer, C. V. Lopez, T. Thiounn and R. C. Smith, Mater. Adv., 2020, 1, 1665 under a Creative Commons Attribution-NonCommercial 3.0 Unported Licence.; Figure S3. The manner in which terpenoid-sulfur composites were fabricates for tensile testing was analogous to that used for compressive testing (Figure S3), but using dog bone-shaped moulds (A). Dimensions of these dog bone-shaped samples were consistent for all materials measured (B).

Author Contributions: Conceptualization, R.C.S.; methodology, R.C.S.; formal analysis, R.C.S. and C.P.M.; investigation, R.C.S. and C.P.M.; resources, R.C.S.; data curation, C.P.M.; writing-original draft preparation, R.C.S. and C.P.M.; writing-review and editing, R.C.S. and C.P.M.; supervision, R.C.S.; funding acquisition, R.C.S. Both authors have read and agreed to the published version of the manuscript.

Funding: This research was funded by The National Science Foundation grant number CHE-1708844.

Conflicts of Interest: The authors declare no conflict of interest.

\section{References}

1. Wilbon, P.A.; Chu, F.; Tang, C. Progress in Renewable Polymers from Natural Terpenes, Terpenoids, and Rosin. Macromol. Rapid Commun. 2013, 34, 8-37. [CrossRef] [PubMed]

2. Matsumura, A.; Yang, F.; Goto, H. Synthesis of a Terpene-Based New Chiral Inducer and Preparation of an Asymmetric Polymer. Polymers 2015, 7, 147-155. [CrossRef]

3. Nguyen, H.T.H.; Qi, P.; Rostagno, M.; Feteha, A.; Miller, S.A. The quest for high glass transition temperature bioplastics. J. Mater. Chem. A 2018, 6, 9298-9331. [CrossRef]

4. Della Monica, F.; Kleij, A.W. From terpenes to sustainable and functional polymers. Polym. Chem. 2020, 11, 5109-5127. [CrossRef]

5. Kamigaito, M.; Satoh, K. Sustainable Vinyl Polymers via Controlled Polymerization of Terpenes. In Sustainable Polymers from Biomass; John Wiley \& Sons: Weinheim, Germany, 2017; pp. 55-90.

6. Bruneau, C.; Fischmeister, C. Alkene metathesis for transformations of renewables. In Organometallic Organometallics for Green Catalysis; Springer: Cham, Switzerland, 2019; pp. 77-102.

7. Song, S.H. Influence of eco-friendly processing aids on silica-based rubber composites. Appl. Sci. 2020, 10, 7244. [CrossRef]

8. Manoharan, P.; Naskar, K. Eco-friendly composites derived from naturally occurring molecules in promoting dispersion of nanosized silica particulates. Polym. Compos. 2019, 40, 871-883. [CrossRef]

9. Wu, G.-m.; Kong, Z.-w.; Chen, J.; Huo, S.-p.; Liu, G.-f. Preparation and properties of waterborne polyurethane/epoxy resin composite coating from anionic terpene-based polyol dispersion. Prog. Org. Coat. 2014, 77, 315-321. [CrossRef]

10. Maladeniya, C.P.; Karunarathna, M.S.; Lauer, M.K.; Lopez, C.V.; Thiounn, T.; Smith, R.C. A Role for Terpenoid Cyclization in the Atom Economical Polymerization of Terpenoids with Sulfur to Yield Durable Composites. Mater. Adv. 2020, 1, 1665-1674. [CrossRef]

11. Lauer, M.K.; Tennyson, A.G.; Smith, R.C. Green Synthesis of Thermoplastic Composites from a Terpenoid-Cellulose Ester. ACS Appl. Polym. Mater. 2020, 2, 3761-3765. [CrossRef]

12. Chung, W.J.; Griebel, J.J.; Kim, E.T.; Yoon, H.; Simmonds, A.G.; Ji, H.J.; Dirlam, P.T.; Glass, R.S.; Wie, J.J.; Nguyen, N.A.; et al. The use of elemental sulfur as an alternative feedstock for polymeric materials. Nat. Chem. 2013, 5, 518-524. [CrossRef]

13. Zhang, Y.; Glass, R.S.; Char, K.; Pyun, J. Recent advances in the polymerization of elemental sulphur, inverse vulcanization and methods to obtain functional Chalcogenide Hybrid Inorganic/Organic Polymers (CHIPs). Polym. Chem. 2019, 10, 4078-4105. [CrossRef]

14. Kleine, T.S.; Glass, R.S.; Lichtenberger, D.L.; MacKay, M.E.; Char, K.; Norwood, R.A.; Pyun, J. 100th Anniversary of Macromolecular Science Viewpoint: High Refractive Index Polymers from Elemental Sulfur for Infrared Thermal Imaging and Optics. ACS Macro Lett. 2020, 9, 245-259. [CrossRef]

15. Duarte, M.E.; Huber, B.; Theato, P.; Mutlu, H. The unrevealed potential of elemental sulfur for the synthesis of high sulfur content bio-based aliphatic polyesters. Polym. Chem. 2020, 11, 241-248. [CrossRef]

16. Worthington, M.J.H.; Kucera, R.L.; Chalker, J.M. Green chemistry and polymers made from sulfur. Green Chem. 2017, 19, $2748-2761$. [CrossRef]

17. Chalker, J.M.; Worthington, M.J.H.; Lundquist, N.A.; Esdaile, L.J. Synthesis and Applications of Polymers Made by Inverse Vulcanization. Top. Curr. Chem. 2019, 377, 16. [CrossRef] 
18. Smith, A.D.; Smith, R.C.; Tennyson, A.G. Carbon-Negative Polymer Cements by Copolymerization of Waste Sulfur, Oleic Acid, and Pozzolan Cements. Sustain. Chem. Pharm. 2020, 16, 100249. [CrossRef]

19. Gutarowska, B.; Piotrowska, M.; Kozirog, A.; Berlowska, J.; Dziugan, P.; Kotynia, R.; Bielinski, D.; Anyszka, R.; Wreczycki, J. New Sulfur Organic Polymer-Concrete Composites Containing Waste Materials: Mechanical Characteristics and Resistance to Biocorrosion. Materials 2019, 12, 2602. [CrossRef]

20. Mohammed, S.; Poornima, V. Strength and durability study of sulphur concrete with replaced fine aggregate. Mater. Today: Proc. 2018, 5, 23888-23897. [CrossRef]

21. Mohamed, A.-M.O.; Gamal, M.E. Sulfur Concrete for the Construction Industry; J. Ross Publishing: Fort Lauderdale, FL, USA, 2010; p. 424.

22. Okumura, H.A. Early sulfur concrete installations. Concr. Int. 1998, 20, 72-75.

23. Weber, H.H.; McBee, W.C.; Krabbe, E.A. Sulfur concrete composite materials for construction and maintenance. Mater. Perform. 1990, 29, 73-77.

24. Pickard, S.S. Sulfur concrete for acid resistance. Chem. Eng. 1985, 92, 77-78.

25. Lauer, M.K.; Tennyson, A.G.; Smith, R.C. Inverse vulcanization of octenyl succinate-modified corn starch as a route to biopolymersulfur composites. Mater. Adv. 2021, 2, 2391-2397. [CrossRef]

26. Thiounn, T.; Lauer, M.K.; Karunarathna, M.S.; Tennyson, A.G.; Smith, R.C. Copolymerization of a Bisphenol a Derivative and Elemental Sulfur by the RASP Process. Sustain. Chem. 2020, 1, 183-197. [CrossRef]

27. Thiounn, T.; Karunarathna, M.S.; Slann, L.M.; Lauer, M.K.; Smith, R.C. Sequential Crosslinking for Mechanical Property Development in High Sulfur Content Composites. J. Polym. Sci. 2020, 58, 1347-1364. [CrossRef]

28. Smith, A.D.; McMillin, C.D.; Smith, R.C.; Tennyson, A.G. Copolymers by Inverse Vulcanization of Sulfur with Pure or Technical Grade Unsaturated Fatty Acids. J. Polym. Sci. 2020, 58, 438-445. [CrossRef]

29. Lopez, C.V.; Maladeniya, C.P.; Smith, R.C. Lithium-Sulfur Batteries: Advances and Trends. Electrochem 2020, 1, 226-259. [CrossRef]

30. Lauer, M.K.; Karunarathna, M.S.; Tennyson, A.G.; Smith, R.C. Robust, remeltable and remarkably simple to prepare biomasssulfur composites. Mater. Adv. 2020, 1, 2271-2278. [CrossRef]

31. Karunarathna, M.S.; Tennyson, A.G.; Smith, R.C. Facile new approach to high sulfur-content materials and preparation of sulfur-lignin copolymers. J. Mater. Chem. A 2020, 8, 548-553. [CrossRef]

32. Karunarathna, M.S.; Smith, R.C. Valorization of Lignin as a Sustainable Component of Structural Materials and Composites: Advances from 2011 to 2019. Sustainability 2020, 12, 734. [CrossRef]

33. Karunarathna, M.S.; Lauer, M.K.; Tennyson, A.G.; Smith, R.C. Copolymerization of an aryl halide and elemental sulfur as a route to high sulfur content materials. Polym. Chem. 2020, 11, 1621-1628. [CrossRef]

34. Karunarathna, M.S.; Lauer, M.K.; Smith, R.C. Facile route to an organosulfur composite from biomass-derived guaiacol and waste sulfur. J. Mater. Chem. A 2020, 8, 20318-20322. [CrossRef]

35. Yan, P.; Zhao, W.; Zhang, B.; Jiang, L.; Petcher, S.; Smith, J.A.; Parker, D.J.; Cooper, A.I.; Lei, J.; Hasell, T. Inverse vulcanized polymers with shape memory, enhanced mechanical properties, and vitrimer behavior. Angew. Chem. Int. Ed. 2020, 59, 13371-13378. [CrossRef]

36. Wu, X.; Smith, J.A.; Petcher, S.; Zhang, B.; Parker, D.J.; Griffin, J.M.; Hasell, T. Catalytic inverse vulcanization. Nat. Commun. 2019, 10, 10035-10044. [CrossRef] [PubMed]

37. Thiounn, T.; Tennyson, A.G.; Smith, R.C. Durable, acid-resistant copolymers from industrial by-product sulfur and microbiallyproduced tyrosine. RSC Adv. 2019, 9, 31460-31465. [CrossRef]

38. Smith, A.D.; Thiounn, T.; Lyles, E.W.; Kibler, E.K.; Smith, R.C.; Tennyson, A.G. Combining agriculture and energy industry waste products to yield recyclable, thermally healable copolymers of elemental sulfur and oleic acid. J. Polym. Sci. Part A 2019, 57, 1704-1710. [CrossRef]

39. Karunarathna, M.S.; Lauer, M.K.; Thiounn, T.; Smith, R.C.; Tennyson, A.G. Valorization of waste to yield recyclable composites of elemental sulfur and lignin. J. Mater. Chem. A 2019, 7, 15683-15690. [CrossRef]

40. Thiounn, T.; Lauer, M.K.; Bedford, M.S.; Smith, R.C.; Tennyson, A.G. Thermally-healable network solids of sulfur-crosslinked poly(4-allyloxystyrene). RSC Adv. 2018, 8, 39074-39082. [CrossRef]

41. Meyer, B. Solid allotropes of sulfur. Chem. Rev. 1964, 64, 429-451. [CrossRef]

42. Lundquist, N.A.; Tikoalu, A.D.; Worthington, M.J.H.; Shapter, R.; Tonkin, S.J.; Stojcevski, F.; Mann, M.; Gibson, C.T.; Gascooke, J.R.; Karton, A.; et al. Reactive Compression Molding Post-Inverse Vulcanization: A Method to Assemble, Recycle, and Repurpose Sulfur Polymers and Composites. Chem. Eur. J. 2020, 26, 10035-10044. [CrossRef]

43. Worthington, M.J.H.; Shearer, C.J.; Esdaile, L.J.; Campbell, J.A.; Gibson, C.T.; Legg, S.K.; Yin, Y.; Lundquist, N.A.; Gascooke, J.R.; Albuquerque, I.S.; et al. Sustainable Polysulfides for Oil Spill Remediation: Repurposing Industrial Waste for Environmental Benefit. Adv. Sustain. Syst. 2018, 2, 1800024. [CrossRef]

44. Worthington, M.J.H.; Kucera, R.L.; Albuquerque, I.S.; Gibson, C.T.; Sibley, A.; Slattery, A.D.; Campbell, J.A.; Alboaiji, S.F.K.; Muller, K.A.; Young, J.; et al. Laying Waste to Mercury: Inexpensive Sorbents Made from Sulfur and Recycled Cooking Oils. Chem. Eur. J. 2017, 23, 16106. [CrossRef]

45. Orme, K.; Fistrovich, A.H.; Jenkins, C.L. Tailoring Polysulfide Properties through Variations of Inverse Vulcanization. Macromolecules 2020, 53, 9353-9361. [CrossRef] 
46. Herrera, C.; Ysinga, K.J.; Jenkins, C.L. Polysulfides Synthesized from Renewable Garlic Components and Repurposed Sulfur Form Environmentally Friendly Adhesives. ACS Appl. Mater. Interfaces 2019, 11, 35312-35318. [CrossRef] [PubMed]

47. Westerman, C.R.; Jenkins, C.L. Dynamic Sulfur Bonds Initiate Polymerization of Vinyl and Allyl Ethers at Mild Temperatures. Macromolecules 2018, 51, 7233-7238. [CrossRef]

48. Park, S.; Lee, D.; Cho, H.; Lim, J.; Char, K. Inverse Vulcanization Polymers with Enhanced Thermal Properties via Divinylbenzene Homopolymerization-Assisted Cross-Linking. ACS Macro Lett. 2019, 8, 1670-1675. [CrossRef]

49. Smith, J.A.; Green, S.J.; Petcher, S.; Parker, D.J.; Zhang, B.; Worthington, M.J.H.; Wu, X.; Kelly, C.A.; Baker, T.; Gibson, C.T.; et al. Crosslinker Copolymerization for Property Control in Inverse Vulcanization. Chem. Eur. J. 2019, 25, 10433-10440. [CrossRef] [PubMed]

50. Lauer, M.K.; Karunarathna, M.S.; Tennyson, A.G.; Smith, R.C. Recyclable, Sustainable, and Stronger than Portland Cement: A Composite from Unseparated Biomass and Fossil Fuel Waste. Mater. Adv. 2020, 1, 590-594. [CrossRef] 